\title{
Nucleation Process of Indium on a Copper Electrode
}

\author{
Yonghwa Chung and Chi-Woo Lee* \\ Department of Advanced Materials Chemistry, Korea University, Jochiwon, Choongnam 339-700, Republic of Korea
}

\begin{abstract}
:
The electrodeposition of indium onto a copper electrode from an aqueous sulfate solution containing $\mathrm{In}^{3+}$ was studied by means of cyclic voltammetry and chronoamperometry. Reduction and oxidation of indium on copper were investigated by using cyclic voltammograms at different negative limiting potentials and at different scan rates in cumulative cycles. Cyclic voltammograms indicated that reduction and oxidation processes of indium could involve various reactions. Chronoamperometry was carried out to analyze the nucleation mechanism of indium in the early stage of indium electrodeposition. The non-dimensional plot of the current transients at different potentials showed that the shape of the plot depended on the applied potential. The nucleation of indium at potential step of $-0.6 \sim-0.8 \mathrm{~V}$ was close to progressive nucleation limited by diffusion. However the nondimensional plot of current transients for the indium nucleation showed different behaviors from theoretical curves at the potential step lower than $-0.8 \mathrm{~V}$.
\end{abstract}

Keywords : Indium, Electrodeposition, Reduction, Oxidation, Nucleation

Received September 6, 2013 : Accepted September 26, 2013

\section{Introduction}

Photovoltaic cells are considered to be one of the solutions for eco-friendly and sustainable energy supply. $\mathrm{CuIn}_{\mathrm{x}} \mathrm{Ga}_{1-\mathrm{x}} \mathrm{Se}_{2}$ (CIGS) thin films have been used as absorbent layers of photovoltaic cells due to their high absorption coefficient and direct band gap and stability against photodegeneration. ${ }^{1,2)}$ CIGS thin films of high quality have obtained via physical vapor deposition (PVD); however PVD method is not economic. ${ }^{3)}$ Lots of studies for electrodeposition of CIGS were carried out because this is a preparation method to obtain low cost, high deposition speed and large area thin films. ${ }^{2,4)}$

We are carrying out the studies on the electrodeposition of CIGS and one of our interests is to examine the nucleation mechanism of each element during the electrodeposition of CIGS. ${ }^{5-7)}$ The studies of nucle-

*Corresponding author. Tel.: +82-44-860-1333

E-mail address: cwlee@korea.ac.kr ation via electrochemical means have been carried out as those have the ability to control the degree of supersaturation. ${ }^{8)}$ The studies of the potentiostatic current transient of the electrochemical nucleation and growth have been carried out by Gunawardena, Scharifker, Astley, and Hills et al..$^{8-14)}$ Valderrama et al. ${ }^{15)}$ studied the electrodeposition of indium thin films on $\mathrm{Mo} / \mathrm{Cu}$ substrates using chronoamperometry. They applied their results to the electrocrystallization theories developed by Scharifker et al ${ }^{8-10)}$ and observed that the nucleation of indium on $\mathrm{Mo} / \mathrm{Cu}$ was adjusted to a three-dimensional growth under instantaneous nucleation limited by diffusion. Huang et al. ${ }^{16)}$ observed a two-step film growth behavior during the electrodeposition of indium on copper substrates and proposed a hypothesis involving the $\mathrm{Cu}$-In interdiffusion and the $\mathrm{Cu}$-In alloy formation.

The metal deposition reactions are mostly treated as mass transfer controlled reactions because of the rapid charge-transfer rate of the reactions. In the beginning of the metal deposition, metal ions are transferred through hemispherical diffusion and three-dimen- 
sional nucleation processes on active sites proceed. The nucleation process is terminated by the expansion of diffusion fields and the hemispherical diffusion gives way to the linear diffusion. In the deposition of metal via single potential step the observed current can be related to the number and age of nuclei present. The current-time transient curve obtained during the electrodeposition of a metal usually consists of a rising, a falling portion, and a current maximum. The rising portion of the current transient indicates an increase in current with expansion of the electroactive area either as each independent nucleus grows in size or as the number of nuclei increases. In the falling portion of the current transient, the diffusion zones of adjacent nuclei overlap each other and the hemispherical masstransfer gives way to linear mass-transfer to the planar surface. This stage corresponds to the growth of the deposit.

The theoretical description of early stages of electrolytic phase formation onto a foreign substrate usually considers two extreme cases of nucleation: instantaneous and progressive. ${ }^{8-10)}$ The initial nucleation can be effectively instantaneous or progressive thus the extreme situations of fast nucleation rate on a small number of active sites or slow nucleation rate on a large number of active sites can occur. The models for the electrochemical nucleation with diffusion-controlled growth were established on the basis of the concept of planar diffusion zones and the use of Avrami's theorem. ${ }^{8)}$

Hills et al. derived expressions for the potentiostatic current time relation as the diffusion is (hemi) spherical ${ }^{12)}$ not linear. ${ }^{11)}$ When all nuclei may be considered to be born at the same time, i.e., the nucleation is instantaneous, the current at $\mathrm{N}$, hemispherical nuclei, is given by

$$
I(t)=\frac{z F N \pi(2 D c)^{3 / 2} M^{1 / 2} t^{1 / 2}}{\rho^{1 / 2}}
$$

where $\mathrm{zF}$ is molar charge of a depositing species, $\mathrm{D}$ is its diffusion coefficient in $\mathrm{cm}^{2} \mathrm{~s}^{-1}, \mathrm{c}$ its concentration in mol $\mathrm{cm}^{-3}, \mathrm{M}$ its molar mass, and $\rho$ its density. Where fresh nuclei are formed continuously, at the condition of so-called progressive nucleation, current is described by the Eq. (2):

$$
I(t)=\frac{2 z k_{n} N_{0} \pi(2 D c)^{3 / 2} M^{1 / 2} t^{3 / 2}}{3 \rho^{1 / 2}}
$$

where $k_{n}$ is the steady state nucleation rate constant per site, and $\mathrm{N}_{0}$, the number density of active sites. Eqs. (1) and (2) are restricted to the formation of three dimensional nuclei acting as point sinks. However, the overlap of neighbouring diffusion zones occurs, which is responsible for the current maxima in the potentiostatic current-time transient.

Gunawardena et $a l .{ }^{8)}$ proposed a new expression which can describe the potentiostatic current maximum and leads to more reliable values of the nuclear number density. It is considered that hemispherical nuclei on the electrode surface are scattered at random and growing under diffusion control. A hemispherical diffusion zone radiating from each center grows out with a radial velocity expressed by Eq (3):

$$
\delta_{\mathrm{t}}=(\mathrm{kDt})^{1 / 2}
$$

where $\mathrm{k}$ is the numerical constant determined by the conditions of the experiment. The planar area of a single diffusion zone at time $t$, is given by

$$
\mathrm{S}_{\mathrm{t}}=\pi \delta_{\mathrm{t}}^{2}=\pi \mathrm{kDt}
$$

If immediately following time $\mathrm{t}=0, \mathrm{~N}$ centers were nucleated per unit area, the fraction of the area $\left(\theta_{\mathrm{ex}}\right)$ covered by diffusion zones assuming that none overlap, at a later time $\mathrm{t}$, is as followed:

$$
\theta_{\mathrm{ex}}=\mathrm{N} \pi \mathrm{kDt}
$$

The actual fraction (considering the overlap of diffusion zone) of area covered by diffusion zones, $\theta$ can be related to $\theta_{\mathrm{ex}}$ by the Avrami theorem, i.e.,

$$
\theta=1-\exp \left(-\theta_{\mathrm{ex}}\right)=1-\exp (-\mathrm{N} \pi \mathrm{kDt})
$$

The radial flux density of electroactive material through the boundaries of the diffusion zones will be given by the equivalent planar diffusive flux to an electrode of fractional area, $\theta$ and Cottrell's equation [eq. (7)] can be applied to the case of linear diffusion control. The current to the whole electrode surface is therefore:

$$
\begin{aligned}
& I=\frac{z F D^{1 / 2} c \theta}{\pi^{1 / 2} t^{1 / 2}} \\
& I=\left(\frac{z F D^{1 / 2} c}{\pi^{1 / 2} t^{1 / 2}}\right)[1-\exp (-N \pi k D t)]
\end{aligned}
$$


At short time, $\mathrm{N} \pi \mathrm{kDt}<<1(\mathrm{Nt} \rightarrow 0)$ :

$$
1-\exp (-\mathrm{N} \pi \mathrm{kDt})=\mathrm{N} \pi \mathrm{kDt}
$$

In the limit $\mathrm{Nt} \rightarrow 0$, the current must be identical to the current corresponding to $\mathrm{N}$ isolated hemispherical nuclei, for instantaneous nucleation:

$$
\begin{aligned}
& \mathrm{I}_{\mathrm{Nt} \rightarrow 0}= \mathrm{zFD} \mathrm{D}^{3 / 2} \mathrm{cN} \pi^{1 / 2} \mathrm{kt}^{1 / 2} \\
& \frac{\mathrm{NzF} \pi(2 \mathrm{Dc})^{3 / 2} \mathrm{M}^{1 / 2} \mathrm{t}^{1 / 2}}{\rho^{1 / 2}} \\
& \mathrm{k}=\left(\frac{8 \pi \mathrm{cM}}{\rho}\right)^{1 / 2}
\end{aligned}
$$

For the nucleation is progressive, current is as followed:

$$
\begin{aligned}
& N(t)=A N_{\infty} t \\
& \theta_{e x}=\int_{0}^{t} A N_{\infty} \pi k^{\prime} D t d t=\frac{A N_{\infty} \pi k^{\prime} D t^{2}}{2} \\
& I=\left(\frac{z F D^{1 / 2} c}{\pi^{1 / 2} t^{1 / 2}}\right)\left[1-\exp \left(-\frac{\mathrm{AN}_{\infty} \pi \mathrm{k}^{\prime} D t^{2}}{2}\right)\right]
\end{aligned}
$$

As $\mathrm{AN}_{\infty} \mathrm{t}$ is limited to 0 , the current become equivalent to the current of $\mathrm{N}$ isolated hemispherical nuclei:

$$
\begin{aligned}
& \left(\frac{\mathrm{zFD}^{1 / 2} \mathrm{c}}{\pi^{1 / 2} \mathrm{t}^{1 / 2}}\right)\left(\frac{\mathrm{AN}_{\infty} \pi \mathrm{k}^{\prime} \mathrm{Dt}^{2}}{2}\right) \\
& =\frac{2 \mathrm{zFAN}_{\infty} \pi(2 \mathrm{Dc})^{3 / 2} \mathrm{M}^{1 / 2} \mathrm{t}^{3 / 2}}{3 \rho^{1 / 2}} \\
& \mathrm{k}^{\prime}=\frac{4}{3}\left(\frac{8 \pi \mathrm{cM}}{\rho}\right)^{1 / 2}
\end{aligned}
$$

The maximum current, $\mathrm{I}_{\max }$ and the maximum time, $\mathrm{t}_{\max }$, corresponding to the maximum in a current transient can be evaluated by equating the first derivative of each current-time relation to zero $(\mathrm{dI} / \mathrm{dt}=0)$. The solutions of $t_{\max }$ and $I_{\max }$ were found by approximant methods. For the instantaneous nucleation, $t_{\max }$ and $I_{\max }$ were given by following relations:

$$
\begin{aligned}
& \mathrm{t}_{\max }=\frac{1.2564}{\mathrm{~N} \pi \mathrm{kD}} \\
& \mathrm{I}_{\max }=0.6382 \mathrm{zFDc}(\mathrm{kN})^{1 / 2}
\end{aligned}
$$

In the case of progressive nucleation, they are as followed:

$$
\begin{aligned}
& \mathrm{t}_{\max }=\left(\frac{4.6733}{\mathrm{AN}_{\infty} \pi \mathrm{k}^{\prime} \mathrm{D}}\right)^{1 / 2} \\
& \mathrm{I}_{\max }=0.4615 \mathrm{zD}^{3 / 4} \mathrm{c}\left(\mathrm{k}^{\prime} \mathrm{AN}_{\infty}\right)^{1 / 4}
\end{aligned}
$$

The product of $\mathrm{I}_{\max }^{2}$ and $\mathrm{t}_{\max }$ does not contain the quantities $\mathrm{k}, \mathrm{k}$, $\mathrm{AN}_{\infty}$, or $\mathrm{N}$ and is therefore a convenient diagnostic criterion to determine whether the nucleation process has been stopped or is still progressing.

$$
\begin{aligned}
& \mathrm{I}_{\max }^{2} \mathrm{t}_{\max }=0.1629(\mathrm{zFc})^{2} \mathrm{D} \\
& \mathrm{I}_{\text {max }}{ }^{2} \mathrm{t}_{\max }=0.2598(\mathrm{zFc})^{2} \mathrm{D}
\end{aligned}
$$

The current expressions for the instantaneous and progressive cases given by eq. (8) and eq. (14) can be modified as the non-dimension expressions of current density to time relation as followed:

$\left(\frac{\mathrm{J}}{\mathrm{J}_{\mathrm{m}}}\right)^{2}=\left(\frac{1.9542}{\mathrm{t} / \mathrm{t}_{\mathrm{m}}}\right)\left[1-\exp \left(-1.2564\left(\frac{\mathrm{t}}{\mathrm{t}_{\mathrm{m}}}\right)\right)\right]^{2}$ (instantaneous

sive $\left.)^{\left(\frac{\mathrm{J}}{\mathrm{m}^{\mathrm{m}}}\right.}\right)^{2}=\left(\frac{1.2254}{\mathrm{t} / \mathrm{t}_{\mathrm{m}}}\right)\left[1-\exp \left(-2.3367\left(\frac{\mathrm{t}}{\mathrm{t}_{\mathrm{m}}}\right)\right)^{2}\right]^{2}($ progres-

According to the earlier literature, ${ }^{15)}$ the nucleation of indium on a $\mathrm{Mo} / \mathrm{Cu}$ substrate in a bath containing $\mathrm{Cl}^{-}$anion was instantaneous nucleation limited by diffusion. In this study, we have tried to investigate the nucleation process of indium in the early stage of the electrodeposition of indium on a copper electrode in a bath containing $\mathrm{SO}_{4}{ }^{2-}$ anion. Analysis of the nucleation mechanism during the electrodeposition of indium was based on the results from cyclic voltammetry and chronoamperometry.

\section{Experimental}

Electrochemical studies were performed using cyclic voltammetry and chronoamperometry techniques. Electrochemical measurements were carried out in the three electrode system connected to the potentiostat, Autolab PGSTAT 101. Copper foil was used as the working electrode of electrochemical measurements. The counter electrode used in these measurements was platinum gauze and the reference electrode was $\mathrm{Ag} / \mathrm{AgCl}$ (sat'd $\mathrm{KCl}$ ) electrode. Copper 
foil used in the experiments was soaked in concentrated $\mathrm{H}_{2} \mathrm{SO}_{4}$ for $10 \mathrm{~min}$, washed with de-ionized water, and dried under Ar gas stream. The electrolytic bath consisted of $5 \times 10^{-3} \mathrm{M} \mathrm{In}_{2}\left(\mathrm{SO}_{4}\right)_{3}, 0.1 \mathrm{M} \mathrm{K}_{2} \mathrm{SO}_{4}$, and $0.01 \mathrm{M} \mathrm{H}_{2} \mathrm{SO}_{4}$ was de-oxygenated for $30 \mathrm{~min}$ with Ar gas before electrochemical measurements. Electrochemical measurements were carried out under Ar atmosphere.

\section{Results and Discussion}

The electrodeposition and dissolution of indium were investigated via cyclic voltammograms obtained at different negative limiting potentials. In the presence of halide anions, $\mathrm{In}^{3+}$ ions form complexes of various coordination number. ${ }^{17-19)}$ The reduction of $\mathrm{In}^{3+}$ in a complex requires more negative potential due to the stability via complexation. ${ }^{20)}$ We carried out cyclic voltammetry of indium under noncomplexing circumstance of an acidic solution containing $5 \times 10^{-3} \mathrm{M} \mathrm{In}_{2}\left(\mathrm{SO}_{4}\right)_{3}$, $0.1 \mathrm{M} \mathrm{K}_{2} \mathrm{SO}_{4}$, and $0.01 \mathrm{M} \mathrm{H}_{2} \mathrm{SO}_{4}$.

Fig. 1 shows that in the forward scan of negative direction, the current densities increase slowly in the potential range of $-0.15 \mathrm{~V} \geq \mathrm{E} \geq-0.55 \mathrm{~V}$ and increase rapidly in the potential range of $-0.55 \mathrm{~V} \geq \mathrm{E} \geq-0.75 \mathrm{~V}$. In the potential range from $-0.15 \mathrm{~V}$ to $-0.55 \mathrm{~V}$, increase of negative current density does not indicate the metallic depositing of indium. In this potential range, a response of negative current density is due to the capacitive behavior. ${ }^{15)}$ The standard potentials of $\operatorname{In}(\mathrm{III}) / \operatorname{In}(0)$, $\mathrm{In}(\mathrm{III}) / \operatorname{In}(\mathrm{I})$, and $\operatorname{In}(\mathrm{I}) / \operatorname{In}(0)$ are $-0.338 \mathrm{~V},-0.443 \mathrm{~V}$,

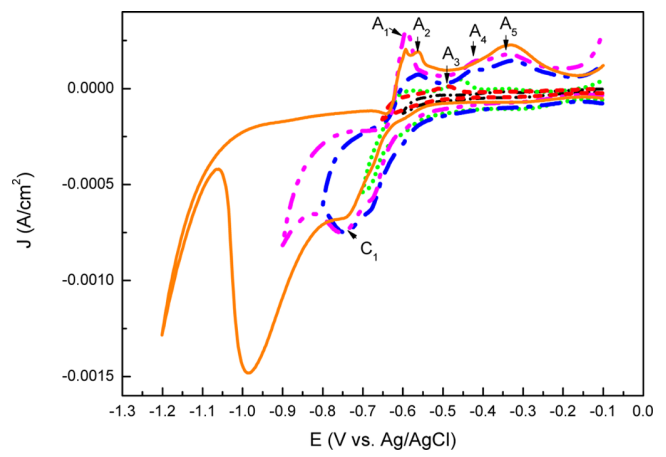

Fig. 1. Cyclic voltammograms obtained on $\mathrm{Cu}$ electrodes in $0.005 \mathrm{M} \mathrm{In}_{2}\left(\mathrm{SO}_{4}\right)_{3}, 0.1 \mathrm{M} \mathrm{K}_{2} \mathrm{SO}_{4}$, and $0.01 \mathrm{M} \mathrm{H}_{2} \mathrm{SO}_{4}$ solutions at a scan rate of $10 \mathrm{mV} / \mathrm{s}$, at different negative limiting potentials, $E_{-\lambda}$ (a) (---) $-0.60 \mathrm{~V}$, (b) (-- -) $-0.65 \mathrm{~V}$, (c) $(\cdots \cdots)-0.70 \mathrm{~V},(\mathrm{~d})(-\cdots-)-0.8 \mathrm{~V},(\mathrm{e})(-\cdots-)-0.9 \mathrm{~V}$, and (f) $(-)-1.2 \mathrm{~V}$. and $-0.14 \mathrm{~V}$ vs. SHE, respectively. ${ }^{21)}$ It is considered that in the potential range from $-0.55 \mathrm{~V}$ to $-0.75 \mathrm{~V}, \mathrm{In}^{3+}$ is reduced according to the reaction (25) and/or a sequential reaction of reactions (26) and (27):

$$
\begin{aligned}
& \mathrm{In}^{3+}+3 \mathrm{e} \rightarrow \mathrm{In}^{0} \\
& \mathrm{In}^{3+}+2 \mathrm{e} \rightarrow \mathrm{In}^{+} \\
& \mathrm{In}^{+}+\mathrm{e} \rightarrow \mathrm{In}^{0}
\end{aligned}
$$

In the reverse scan of positive direction, several peaks of various current densities appear when the negative limiting potential $\left(\mathrm{E}_{-\lambda}\right)$ is more negative than $-0.60 \mathrm{~V}$. These peaks are associated with the stripping of indium. As $E_{-\lambda}$ is $-0.60 \mathrm{~V}$, any anodic peaks are not observed [Fig. 1(a)]. As the negative limiting potentials are $-0.65 \mathrm{~V}$ and $-0.70 \mathrm{~V}$, one broad peak, $A_{3}$ is observed [Fig. 1(b) and (c)]. When indium is deposited on a $\mathrm{Cu}$ substrate, in the beginning of deposition indium with $\mathrm{Cu}$ of a substrate forms CuIn alloy and then indium deposits form indium films. ${ }^{15,16)}$ Therefore $A_{3}$ peak can be related to the dissolution of indium from the CuIn alloy. The first anodic peak, $\mathrm{A}_{1}$ shown at about $-0.6 \mathrm{~V}$ in Fig. $1(\mathrm{~d})$-(f) can be considered to be due to the oxidation of $\operatorname{In}^{0}$ to $\operatorname{In}^{3+}$. However the first anodic peak is sometimes broad [Fig. 1(d)] or splits into two peaks [Fig. 1(f)]. In the range from $-0.6 \mathrm{~V}$ to $-0.5 \mathrm{~V}$, the oxidations of $\operatorname{In}^{0}$ to $\mathrm{In}^{3+}$ and $\mathrm{In}^{+}$to $\mathrm{In}^{3+}$ are possible. Multiple cyclic voltammograms from $-0.1 \mathrm{~V}$ to $-0.9 \mathrm{~V}$ were obtained as in Fig. 2. The current density of the first anodic peak increased with increasing number of scan. This means that the concentration of oxidative species such as $\mathrm{In}^{0}$ and $\mathrm{In}^{+}$increase with repetition of scan. In the first scan, indium is deposited on the $\mathrm{Cu}$

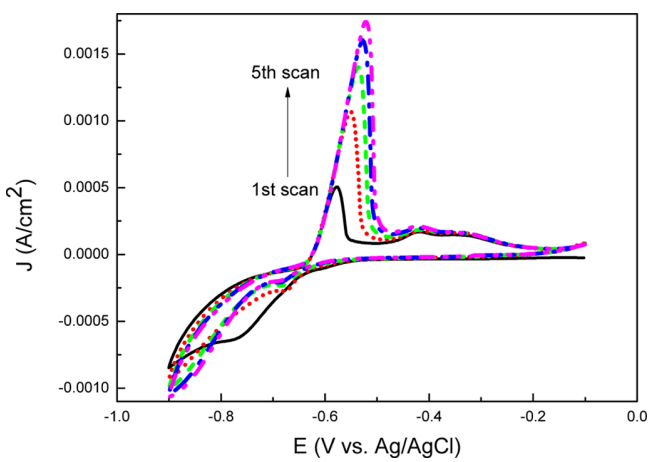

Fig. 2. Multiple cyclic voltammogram obtained on $\mathrm{Cu}$ electrodes in $0.005 \mathrm{M} \mathrm{In}_{2}\left(\mathrm{SO}_{4}\right)_{3}, 0.1 \mathrm{M} \mathrm{K}_{2} \mathrm{SO}_{4}$, and $0.01 \mathrm{M}$ $\mathrm{H}_{2} \mathrm{SO}_{4}$ solutions at a scan rate of $10 \mathrm{mV} / \mathrm{s}$. $\mathrm{E}_{-\lambda}$ is $-0.9 \mathrm{~V}$. 
substrate but after second scan indium is deposited on deposited indium surface. Therefore it is known that after second scan the dissolution of indium metal occurs in the potential range from $-0.6 \mathrm{~V}$ to $-0.5 \mathrm{~V}$ and that the anodic peak current density corresponding to the dissolution of indium metal on indium surface increase with increasing number of scan.

$\mathrm{In}^{+}$ions around the electrode can be formed via reaction (26) and proportionation reaction. ${ }^{22)}$ Proportionation reaction of indium deposits and $\mathrm{In}^{3+}$ produces $\mathrm{In}^{+}$as following:

$$
\operatorname{In}^{3+}+2 \operatorname{In}^{0} \rightarrow 3 \operatorname{In}^{+}
$$

It can be suggested that the peaks, $A_{1}$ and $A_{2}$ in Fig. 1 correspond to the oxidations of $\operatorname{In}^{+}$and $\operatorname{In}^{0}$ to $\operatorname{In}^{3+}$, respectively. In Fig. 1, the peaks, $\mathrm{A}_{4}$ and $\mathrm{A}_{5}$ at more positive potentials can be due to the oxidation of $\operatorname{In}^{0}$ to $\mathrm{In}^{+}$or the oxidation of more noble materials. ${ }^{16)}$ When the negative limiting potential was more negative than $-1.4 \mathrm{~V}\left(\mathrm{E}_{-\lambda} \leq-1.4 \mathrm{~V}\right)$, silvery In metal on the electrode was observed during forward scan and anodic peaks around $-0.45 \mathrm{~V}$ appeared during cathodic scan in the $2^{\text {nd }}$ and $3^{\text {rd }}$ scan as shown in the inset in Fig. 3. In the $3^{\text {rd }}$ scan these peaks were enhanced. These peaks are considered to be due to the oxidations of $\operatorname{In}^{0}$ to $\mathrm{In}^{+}$ and/or $\operatorname{In}^{3+}$.

The reduction peaks besides the $C_{1}$ peak of Fig. 1 appear at the potential which is more negative than $-0.8 \mathrm{~V}$ as shown in Fig. 1(e), (f) and Fig. 3. Fig. 1 shows that the anodic peak current density increased with the change of negative limiting potential to the negative direction and the silvery indium metal occurred during forward

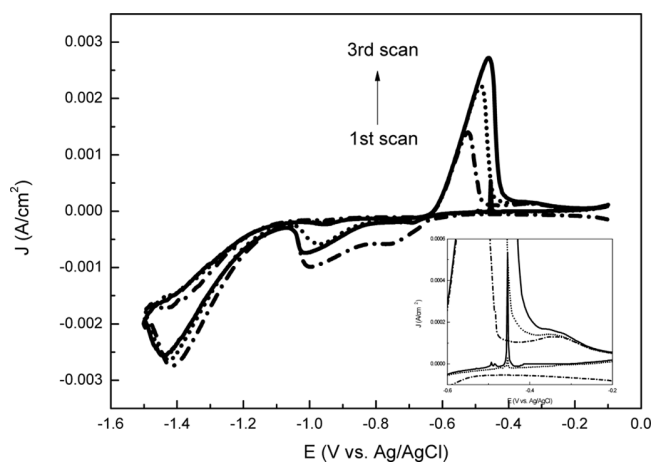

Fig. 3. Multiple cyclic voltammograms obtained on $\mathrm{Cu}$ electrodes in $0.005 \mathrm{M} \mathrm{In}_{2}\left(\mathrm{SO}_{4}\right)_{3}, 0.1 \mathrm{M} \mathrm{K}_{2} \mathrm{SO}_{4}$, and $0.01 \mathrm{M}$ $\mathrm{H}_{2} \mathrm{SO}_{4}$ solutions at a scan rate of $10 \mathrm{mV} / \mathrm{s}$. $\mathrm{E}_{-\lambda}$ is $-1.4 \mathrm{~V}$. scan of cyclic voltammetry to the potential which is more negative than $-1.4 \mathrm{~V}$. It is suggested that these cathodic peaks are related to the reduction of indium.

Chronoamperometry was performed in order to investigate the nucleation and growth mechanism of indium. Chronoamperograms during the deposition of indium on copper electrodes in $0.005 \mathrm{M} \mathrm{In}_{2}\left(\mathrm{SO}_{4}\right)_{3}$ solutions were obtained at single potential step from $-0.6 \mathrm{~V}$ to $-1.0 \mathrm{~V}$ for $20 \mathrm{~s}$, as shown in Fig. 4 . We can estimate the mass of indium deposits, the number of indium monolayer, and the film thickness from the current transients in Fig. 4 by assuming that all the reduction charge is consumed by deposition of indium. ${ }^{15)}$ If the electrode surface area occupied by one indium atom is $8.76 \times 10^{-16} \mathrm{~cm}^{2}$, indium atoms of $1.89 \times 10^{-9} \mathrm{~mol}$ would form a monolayer of $1 \mathrm{~cm}^{2}$, thus the charge needed to form indium monolayer of $1 \mathrm{~cm}^{2}$ ( $\mathrm{Q}_{\text {monolayer }}$ ) would be $5.48 \times 10^{-4} \mathrm{C}$. The film thickness can be calculated using Faraday law normalized to a unit surface $^{23)}$ :

$$
\mathrm{h}=\frac{\mathrm{MQ}}{\rho \mathrm{zF}}=5.43 \times 10^{-5} \mathrm{Q}
$$

where, $\mathrm{h}$ is the film thickness, $\mathrm{z}$ is the number of exchanged electrons $(\mathrm{z}=3), \mathrm{M}$, molar mass of indium is $114.82 \mathrm{~g} / \mathrm{mol}$, indium density $\rho=7.31 \mathrm{~g} / \mathrm{cm}^{3}$, and $\mathrm{Q}$ is the measured negative charge density $\left(\mathrm{Q}=\mathrm{Q}_{\mathrm{c}}\right)$. Table 1 includes the mass of indium deposits, the number of monolayer and the thickness of the film formed from indium deposited for $20 \mathrm{~s}$ at different applied potentials.

It is shown that the maximum current density

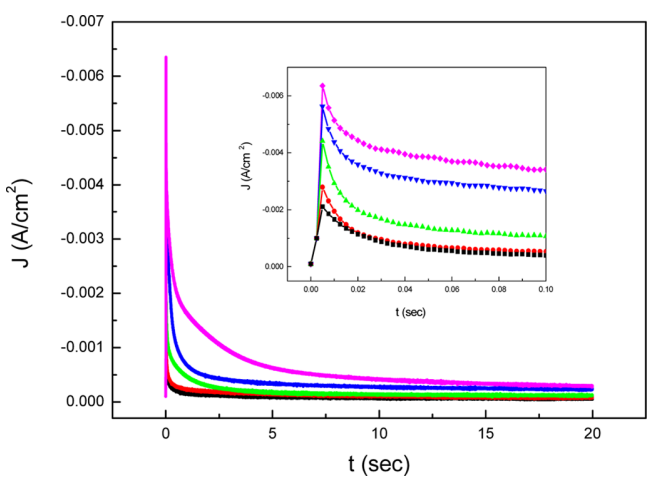

Fig. 4. Potentiostatic current transients for the reduction of $0.010 \mathrm{M} \mathrm{In}^{3+}$ for $20 \mathrm{~s}$ on $\mathrm{Cu}$ electrodes at potentials of -0.60 (black, $\mathbf{\square}),-0.70$ (red, $),-0.8$ (green, $\mathbf{\Lambda}$ ), -0.9 (blue, $\boldsymbol{\nabla}$ ), and $-1.0 \mathrm{~V}$ (pink, $\bullet$ ) vs. $\mathrm{Ag} / \mathrm{AgCl}$. 
Table 1. The dependence of the reduction charge density $\left(\mathrm{Q}_{\mathrm{c}}\right)$, mass of In deposits, the number of monolayers, and the film thickness on the applied potential from current transient in Fig. 4

\begin{tabular}{ccccc}
\hline $\begin{array}{c}\mathrm{E}(\mathrm{V} v \mathrm{vs} . \\
\mathrm{Ag} / \mathrm{AgCl})\end{array}$ & $\begin{array}{c}\mathrm{Q}_{\mathrm{c}} \\
\left(\mathrm{mC} / \mathrm{cm}^{2}\right)\end{array}$ & $\begin{array}{c}\text { Mass of In } \\
\text { deposits }(\mathrm{g})\end{array}$ & $\begin{array}{c}\text { No. of } \\
\text { monolayer }\end{array}$ & $\begin{array}{c}\text { Film thick- } \\
\text { ness }(\mathrm{cm})\end{array}$ \\
\hline-0.60 & 1.83 & $7.26 \times 10^{-7}$ & 3 & $9.89 \times 10^{-8}$ \\
-0.70 & 2.57 & $1.02 \times 10^{-6}$ & 5 & $1.39 \times 10^{-7}$ \\
-0.80 & 3.80 & $1.51 \times 10^{-6}$ & 7 & $2.05 \times 10^{-7}$ \\
-0.90 & 7.10 & $2.82 \times 10^{-6}$ & 13 & $3.84 \times 10^{-7}$ \\
-1.00 & 12.2 & $4.84 \times 10^{-6}$ & 22 & $6.59 \times 10^{-7}$ \\
\hline
\end{tabular}

depends on the magnitude of the applied potential in Fig. 4. The maximum current density increases with the applied potential however the time at which current density shows maximum value $\left(\mathrm{t}_{\max }\right)$ is independent on the applied potential. All the $t_{\max }$ values of current transients are the same in spite of the variable applied potentials as seen in the inset plots. Scharifker and Hills ${ }^{9)}$ showed that the potentiostatic current transient of the three-dimensional nucleation of metal has the maximum current and $t_{\max }$ those depend on the overpotential. Fig. 5 shows simulated current transients for the deposition of $\mathrm{In}^{3+}$ based on the Eqs. (8) and (14). The various current transient curves may be obtained from different number densities of nuclei instead of the different overpotentials because the number density of nuclei depends on the overpotential. ${ }^{13,24)}$ These simulated current transient curves are not the same as the curves obtained from our experiments. It can be known that the maximum current increases and the maximum time decreases with the overpotential. According to Eqs. (21) and (22), $\mathrm{I}_{\max }^{2} \cdot \mathrm{t}_{\max }$ must be constant under the condition of constant concentration and constant diffusion coefficient. ${ }^{8,25)}$ If we know whether the nucleation process is instantaneous or progressive we can find the diffusion coefficient from the values of $\mathrm{I}_{\max }{ }^{2} \cdot \mathrm{t}_{\max }$. The value of $\mathrm{I}_{\max }{ }^{2} \cdot \mathrm{t}_{\max }$ obtained from potentiostatic current transients in Fig. 4 and Fig. 5 are listed in Table 2. We can find that the value of $\mathrm{I}_{\max }^{2} \cdot t_{\max }$ obtained from our experiment increases ten-times as the applied potential is changed from $-0.6 \mathrm{~V}$ to $-1.0 \mathrm{~V}$ but the values of $\mathrm{I}_{\max }{ }^{2} \cdot \mathrm{t}_{\max }$ from simulated current transients are almost constant for each situation. The fact that the values of $\mathrm{I}_{\max }{ }^{2} \cdot \mathrm{t}_{\max }$ are not constant means that the assumption of the indium deposition reaction limited by mass transportation is not satisfied or the diffusion coefficient can varies with the applied poten-
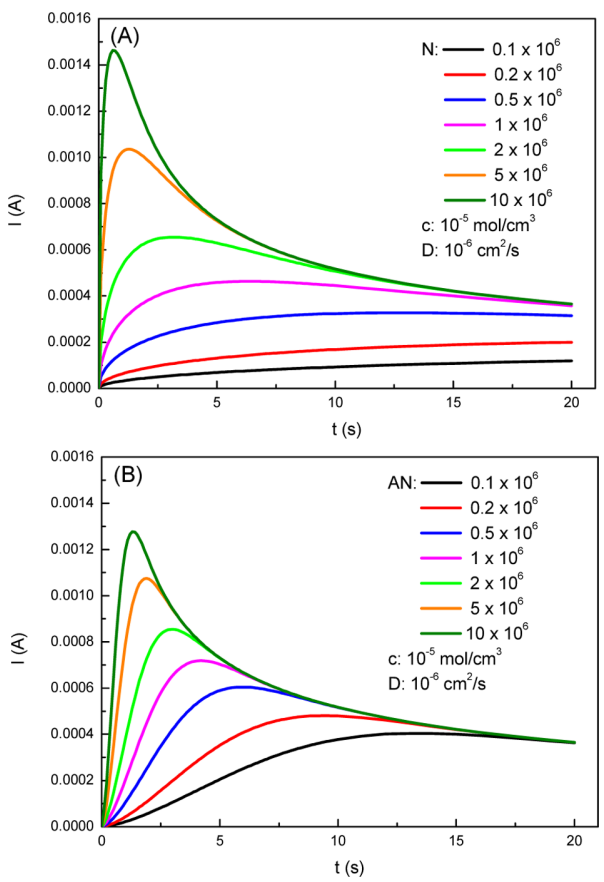

Fig. 5. Simulated current transients for 3-dimensional instantaneous (A) and progressive (B) nucleations with diffusion controlled growth according to Eqs. (8) and (14) for the electrodeposition of indium, reaction $(25)$, for $\mathrm{c}=1.0 \times 10^{-5} \mathrm{~mol} /$ $\mathrm{cm}^{3}, \mathrm{D}=1.0 \times 10^{-6} \mathrm{~cm}^{2} / \mathrm{s}, \mathrm{M}=114.82 \mathrm{~g} / \mathrm{mol}, \rho=7.31 \mathrm{~g} / \mathrm{cm}^{3}$, and the values for $\mathrm{N}$ and $\mathrm{AN}_{\infty}$ as indicated.

tials. Valderrama et al. ${ }^{15)}$ calculated the diffusion coefficient of $\mathrm{In}^{3+}$ through Cottrell's equation and Eq. (8). Their results showed that values of the diffusion coefficient depended on the applied potential. MirandaHernandez et $a l_{.}{ }^{26)}$ also found that the diffusion coefficient of electroactive species $\left(\mathrm{Ag}^{+}\right)$varied with the applied potential. As we calculated diffusion coefficients of $\mathrm{In}^{3+}$ at different potentials from Cottrell Eq. and the values of $\mathrm{I}_{\max }{ }^{2} \cdot \mathrm{t}_{\max }$, the values of diffusion coefficient of $\mathrm{In}^{3+}$ were about $10^{-8} \sim 10^{-7} \mathrm{~cm}^{2} \mathrm{~s}^{-1}$ and increased with the applied potential. However these values are quite different from those $\left(\sim 10^{-6} \mathrm{~cm}^{2} \mathrm{~s}^{-1}\right)$ obtained by Valderrama et al.. ${ }^{15)}$ According to Tokoro et $a{ }^{20)}$ the diffusion coefficient of the $\mathrm{In}^{3+}$ complex in aqueous medium of azide which acted as a catalytic ligand was around $6.1 \times 10^{-6} \mathrm{~cm}^{2} \mathrm{~s}^{-1}$. For the reduction of indium complex the electron transfers from the electrode to metal ion occurred through a ligand bridge. In noncomplexing medium, $\mathrm{In}^{3+}$ is present as the aquo complex $\mathrm{In}\left(\mathrm{H}_{2} \mathrm{O}\right)_{6}{ }^{3+}$ and the water molecule is not a good bridge for electron transfer. Thus the electron 
Table 2. Values of $\mathrm{J}_{\max }{ }^{2} \cdot \mathrm{t}_{\max }$ obtained from the current transient data in Fig. 4 and Fig. 5

\begin{tabular}{cccccc}
\hline \multicolumn{2}{c}{ Experimental current transients } & \multicolumn{5}{c}{ Calculated current transients } \\
\hline $\mathrm{E}(\mathrm{V}$ vs. $\mathrm{Ag} / \mathrm{AgCl})$ & $\mathrm{J}_{\max }{ }^{2} \cdot \mathrm{t}_{\max }$ & $\mathrm{N}$ & $\mathrm{J}_{\max }{ }^{2} \cdot \mathrm{t}_{\max }$ & $\mathrm{AN}_{\infty}$ & $\mathrm{J}_{\max }{ }^{2} \cdot \mathrm{t}_{\max }$ \\
\hline-0.60 & $2.21 \times 10^{-8}$ & $0.1 \times 10^{6}$ & & $0.1 \times 10^{6}$ & $2.1 \times 10^{-6}$ \\
-0.70 & $3.89 \times 10^{-8}$ & $0.2 \times 10^{6}$ & $1.4 \times 10^{-6}$ & $0.2 \times 10^{6}$ & $2.2 \times 10^{-6}$ \\
-0.80 & $9.74 \times 10^{-8}$ & $0.5 \times 10^{6}$ & $1.4 \times 10^{-6}$ & $0.5 \times 10^{6}$ & $2.2 \times 10^{-6}$ \\
-0.90 & $1.58 \times 10^{-7}$ & $1 \times 10^{6}$ & $1.4 \times 10^{-6}$ & $1 \times 10^{6}$ & $2.2 \times 10^{-6}$ \\
-1.00 & $2.02 \times 10^{-7}$ & $2 \times 10^{6}$ & $1.4 \times 10^{-6}$ & $2 \times 10^{6}$ & $2.2 \times 10^{-6}$ \\
& & $5 \times 10^{6}$ & $1.4 \times 10^{-6}$ & $5 \times 10^{6}$ & $2.2 \times 10^{-6}$ \\
& & $10 \times 10^{6}$ & $1.3 \times 10^{-6}$ & $10 \times 10^{6}$ & $2.1 \times 10^{-6}$ \\
\hline
\end{tabular}

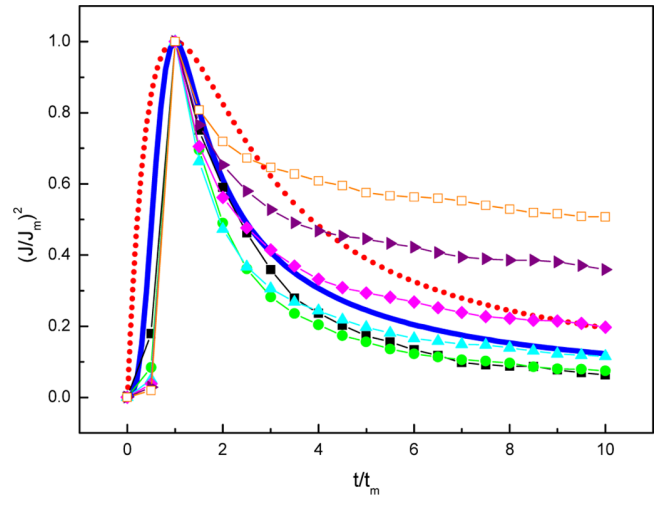

Fig. 6. Non-dimensional $\left(\mathrm{J} / \mathrm{J}_{\mathrm{m}}\right)^{2}$ vs. $\mathrm{t} / \mathrm{t}_{\mathrm{m}}$ plots of the current transients obtained at potential steps of $-0.6(\mathbf{\square}),-0.7(\mathbf{O})$, $-0.8(\mathbf{\Delta}),-0.9(\diamond),-0.95(\triangleright)$, and $-1.0 \mathrm{~V}(\square)$ vs. $\mathrm{Ag} /$ $\mathrm{AgCl}$ in Fig. 4 are compared with the theoretical curves according to eq. (23) (dot line, instantaneous) and (24) (solid line, progressive).

transfers during the reduction of $\operatorname{In}^{3+}$ in sulfate medium become slow. It is suggested that the indium deposition reaction in an aqueous sulfate solution is limited by charge transfer rather than by mass transfer.

As shown in Fig. 6, we obtained the normalized cathodic transients to confirm whether the nucleation mechanism of indium adjust to instantaneous or progressive nucleation. Fig. 6 shows the curves obtained in the range from -0.6 to $-0.8 \mathrm{~V}$ are near progressive, this means that the nucleation of indium corresponds to the situation of slow nucleation rate on a large number of active sites. ${ }^{10)}$ Valderrama et al. ${ }^{15)}$ reported that nucleation process during the electrodeposition of indium on $\mathrm{Mo} / \mathrm{Cu}$ adjusted to a three dimensional growth under instantaneous nucleation limited by diffusion. Our result doesn't agree with Valderrama's results. This result may be attributed to our experiment condition i.e., pure $\mathrm{Cu}$ foil electrode, sulfate electrolyte, $10 \mathrm{mM} \mathrm{In}^{3+}$, and $\mathrm{pH} 1.7$ that was different from their experimental condition. Although slightly different $\mathrm{In}^{3+}$ concentration can hardly affect the nucleation process, we can't make a simple comparison between our results and their results due to the other factors such as electrode surface condition, supporting electrolyte, and $\mathrm{pH}$. The dependence of the nucleation process on the metal ion concentration, ${ }^{24,26,27)}$ the overpotential-dependence of the nucleation, ${ }^{10,28)}$ the different nucleation processes due to the differences in the structure of electrode surfaces, ${ }^{29)}$ and the influence of addition of additives on the nucleation ${ }^{24,30)}$ were studied. The nuclear number density was influenced by supporting electrolytes and their concentrations ${ }^{27}$ and increased with an increase of hydrogen ion concentration. ${ }^{24)}$ Valderrama et al. carried out the electrodeposition of copper on Mo prior to indium deposition in order to improve adhesion of indium. ${ }^{15}$ ) It is considered that the nucleation of indium on $\mathrm{Cu}$ foil can be different from that on $\mathrm{Cu}$-deposited $\mathrm{Mo}$ electrode due to the difference in electrode surface structures. Sobry and Roy observed the different nucleation behaviors of Au on glassy carbon and graphite however there was not a deep discussion about the difference in their literature. ${ }^{29)}$ We want to consider the supporting electrolyte in the deposition bath. In the nucleation of copper the role played by the supporting electrolyte was investigated. ${ }^{27)}$ The use of $\mathrm{NaClO}_{4}, \mathrm{Na}_{2} \mathrm{SO}_{4}$, and $\mathrm{NaNO}_{3}$ as supporting electrolytes brought about only small differences, however the addition of $\mathrm{Cl}^{-}$anion give rise to the decrease of nuclear number density because of the complex formation with $\mathrm{Cu}$ ions, especially $\mathrm{Cu}^{+}$ion. Increase in 
the nuclear number density and decrease in the nucleation rate in the nucleation of indium are expected by the use of $\mathrm{SO}_{4}{ }^{2-}$ anion instead of $\mathrm{Cl}^{-}$anion as a supporting electrolyte. It is considered that the complexation of indium can affect the nucleation of indium thermodynamically and kinetically. We can also notice the several reactions on the copper electrode during the reduction of indium. If only the reduction of $\mathrm{In}^{3+}$ to $\mathrm{In}^{0}$ (indium deposition) takes place on the electrode surface at enough negative potential, the analysis of current transient during indium deposition at single potential step would be simple. The nucleation of materials such as $\mathrm{Pb}$ on $\mathrm{ZnO},{ }^{9}{ }^{9} \mathrm{Cu}_{2} \mathrm{~S}$ on $\mathrm{Cu},{ }^{9} \mathrm{Al}$ on $\mathrm{Cu}$ in ionic liquid ${ }^{14)}$ closely followed theoretical nucleation process by Scharifker. While the nucleation of $\mathrm{Pb}$ on vitreous carbon showed various nucleation processes with overpotential and the nucleation of $\mathrm{Au}$ on glassy carbon exhibited instantaneous and progressive process before and after overlapping of particles, respectively. ${ }^{29)}$ As was discussed earlier, the deposition of indium is done by successive reaction of reactions (26) and (27) as well as reaction (25). Besides $\mathrm{In}^{+}$ can be also produced by proportionation reaction of indium deposits and $\mathrm{In}^{3+}$ [reaction (28)] and the $\mathrm{In}^{+}$ ions in acidic solution are able to proceed the reduction of hydrogen ions according to the reaction $(30)^{31)}$ :

$$
\mathrm{In}^{+}+2 \mathrm{H}^{+} \rightarrow \mathrm{In}^{3+}+\mathrm{H}_{2}
$$

We could observe $\mathrm{H}_{2}$ gas on the electrode surface at the potential step of $\mathrm{E} \leq-0.9 \mathrm{~V}$. Evolution of $\mathrm{H}_{2}$ gas during the indium deposition leads to lower current efficiency. ${ }^{32)}$ The situation of deposition of indium in a sulfate bath is that all the charge consumed on $\mathrm{Cu}$ electrode doesn't match the amount of indium deposits and the nucleation of indium may not be limited by diffusion. The results say that the nucleation mechanism of indium can not apply to the three-dimensional nucleation model established by Scharifker et al.. It is not easy to examine the nucleation mechanism of indium using chronoamperometry because the several reactions can occur concurrently during the electrodeposition of indium and there are little studies for nucleation of metals that have been performed systematically.

Further studies about dependences of nucleation process on the electrode structure, the concentration of $\mathrm{In}^{3+}, \mathrm{pH}$ of electrolytic bath, supporting electrolytes, and additives will be carried out via electrochemical and microscopic measurements.

\section{Conclusions}

Electrochemical measurements were carried out in order to determine the nucleation process of indium. Cyclic voltammograms showed that the reduction and oxidation procedures of indium can include various electrochemical and chemical reactions. The reactions that occur concurrently during deposition of indium make it difficult to analyze nucleation process through current transients. $\mathrm{In}^{+}$ion electroreduced from $\mathrm{In}^{3+}$ can react with hydrogen ion and $\mathrm{In}^{3+}$ can react with $\mathrm{In}^{0}$ chemically. The nucleation process of indium in an acidic bath containing sulfate anion was close to the progressive nucleation at the applied potential from 0.6 to $-0.8 \mathrm{~V}$, however at the lower potential than $0.8 \mathrm{~V}$, the nucleation process of indium escaped the progressive nucleation pattern as shown in Fig. 6. The results about nucleation process of indium did not agree with the results that Valderramma et al. have shown. The nucleation process is considered to be affected by complexation with supporting electrolyte or water molecule.

\section{Acknowledgements}

This work was financially supported by Natural Research Foundation of Korea (2010-0029164).

\section{References}

1. O. Bamiduro, G. Chennamadhava, R. Mundle, R. Konda, B. Robinson, M. Bahoura, and A. K. Pradhan, Solar Energy, 85, 545 (2011).

2. V.S. Saji, S.-M. Lee, and C.-W. Lee, J. Korean Electrochem. Soc., 14, 6170 (2011).

3. I. Repins, M.A. Contreras, B. Egaas, C. DeHart, J. Scharf, C.L. Perkins, B. To, and R. Noufi, Prog. Photovolt: Res. Appl. 16, 235239 (2008).

4. V.S. Saji, I.-H. Choi, and C.-W. Lee, Solar Energy, 85, 26662678 (2011).

5. Y. Chung and C.-W. Lee, J. Electrochem. Sci. Tech., 3, 1 (2012).

6. Y. Chung and C.-W. Lee, J. Electrochem. Sci. Tech., 4, 1 (2013).

7. V.S. Saji and C.-W. Lee, $R S C A d v$, 3, 10058 (2013).

8. G. Gunawardena, G. Hills, I. Montenegro, and B. Scharifker, J. Electroanal. Chem., 138, 225 (1982).

9. B. Scharifker and G. Hills, Electrochim. Acta, 28, 879 (1983).

10. B.R. Scharifker and J. Mostany, J. Electroanal. Chem., 
177, 13 (1984).

11. D.J. Astley, J.A. Harrison, and H.R. Thirsk, Trans. Faraday Soc., 64, 192 (1968).

12. G.J. Hills, D.J. Schiferin, and J. Thompson, Electrochim. Acta, 19, 657 (1974).

13. G. Gunawardena, G. Hills, and I. Montenegro, Electrochim. Acta, 23, 693 (1978).

14. V. Kamavaram and R. Reddy, Light Metals (TMS Annual Meeting and Exhibition), Ed. W. Schneider, 2002, 253 (2002).

15. R.C. Valderrama, M. Miranda-Hernandez, P.J. Sebastian, and A.L. Ocampo, Electrochim. Acta, 53, 3714 (2008).

16. Q. Huang, K. Reuter, S. Amhed, L. Deligianni, L.T. romankiw, S. Jaime, P.-P. Grand, and V. Charrier, J. Electrochem. Soc., 158, D57 (2011).

17. P. Kondziela and J. Biermat, J. Electroanal. Chem., 61, 281 (1975).

18. D.G. Tuck, Pure \& Appl. Chem., 55, 1477 (1983).

19. M. Zeliæ, M. Mlakar, and M. Branica, Anal. Chim. Acta, 289, 299 (1994).

20. R. Tokoro, M. Bertotti, and L. Angnes, Can. J. Chem. 73, 232 (1995)

21. D.R. Lide (ed), CRC Handbook of Chemistry and Physics, $88^{\text {th }}$ ed. CRC Press, Boca Raton, FL, p. 8-20
(2008).

22. L.G. Hepler, Z.Z. Hugus Jr., and W.M. Latimer, J. Am. Chem. Soc., 75, 5652 (1953).

23. S. Omanovic, M. Metikos-Hukovic, Thin Solid Films, 458, 52 (2004).

24. G. Gunawardena, G. Hills, and I. Montenegro, J. Electroanal. Chem., 138, 241 (1982).

25. J. Mostany, J. Mozota, and B.R. Scharifker, J. Electroanal. Chem., 177, 25 (1984).

26. M. Miranda-Hernández, M. Palomar-Pardavé, N. Batina, and I. González, J. Electroanal. Chem., 443, 81 (1998).

27. G. Gunawardena, G. Hills, and I. Montenegro, J. Electroanal. Chem., 184, 357 (1985).

28. B. Scharifker, R. Rugeles, and J. Mozota, Electrochim. Acta, 29, 261 (1984).

29. S. Sobri and S. Roy, J. Eng. Sci. Tech., 3, 62 (2008).

30. A. Radisic, A.C. West, and P.C. Searson, J. Electrochem. Soc., 149, C94 (2002).

31. R.E. Visco, J. Phys. Chem., 69, 202 (1965).

32. S.M. Lee, S. Ikeda, Y. Otsuka, W. Septina, T. Harada, and M. Matsumura, Electrochim. Acta, 79, 189 (2012). 